Global Conferences Series:

Social Sciences, Education and Humanities (GCSSSEH), Volume 6, 2020

International Conference Fakultas Tarbiyah dan Keguruan Universitas Islam Negeri Imam Bonjol Padang (ICFTKUINIBP) 2020

DOI: https://doi.org/10.32698/icftk405

\title{
Implementation Management of Character Education at UniversitasPamulang
}

\section{Implementasi Manajemen Pendidikan Karakter di Universitas Pamulang}

\author{
Yenny Merinatul Hasanah ${ }^{\mathrm{a}}$, Putut Said Permana ${ }^{\mathrm{b}}$ \\ ${ }^{a}$ Universitas Pamulang, Banten, indonesia, ${ }^{b}$ Universitas Pamulang, Indonesia \\ E-mail: dosen01810@unpam.ac.id
}

\begin{abstract}
This research aims to find out the implementation of character education management at Universitas Pamulang and to find out the barrier factors in implementing character education. This research applied qualitative approach. The subjects of this research consisted of the foundation, rector, team of vice rector III, lecturers, and students of Universitas Pamulang. The data in this research were collected by observation, document analyses, and interviews. The technique of data analysis used referred to data analysis of interactive model, which is triangulation. The findings of the implementation of character education management were: First, the planning to grow shared awareness and to equalize the perception on the importance of value or character integration. Second, organizing the distributions of tasks, authorities, and responsibilities to the whole lecturers, especially the lecturers of religion subject and the team of Vice Rector III.Third, mobilizing the academic, non-academic activities; ways and processes to improve the activities. Fourth, controlling; observing what have been achieved and felt by the implementation of education character by the foundation, rector, all lecturers, team of Vice Rector III, religion subject lecturers, and students.Meanwhile there was a barrier in implementing the character education management at UniversitasPamulang. That was the limited human resources that actively implemented the existing programs.
\end{abstract}

Keywords: Implementation, management, character education

\section{PENDAHULUAN}

Pendidikan merupakan upaya sadar dan terencana dalam menyiapkan pembangunan bangsa Indonesia supaya menjadi manusia yang lebih baik. Melalui pendidikan akan mengenal, memahami, menghayati, dan mengamalkan amanat Undang-undang tentang Pendidikan Nasional yang dapat menyiapkan arah perkembangan dan pembangunan masyarakat Indonesia masa depan. Melalui kegiatan bimbingan, pengajaran, pelatihan, serta penggunaan pengalaman diharapkan terjadinya perubahan pada kehidupan masyarakat Indonesia.Pendidikan sering dihubungkan dengan bidang lain seperti hukum, sosial, ekonomi, dan bidang lainnya, hal ini karena pendidikan dianggap sebagai akar dari permasalahan diberbagai bidang. Misalnya permasalahan ekonomi yang terjadi dikalangan bawah maka yang disalahkan adalah jenjang pendidikannya.

Kondisi suatu negara dapat tercermin dari kualitas pendidikannya, bangsa yang berkomitmen terhadap kualitas pendidikan tentu akan menghasilkan sumber daya manusia yang berkompeten sehingga pada jangka panjang dapat meningkatkan perekonomian negaranya. Indonesia sebagai negara berkembang tentu saja akan menjadi negara maju ketika masalah pendidikan dibenahi terlebih dahulu. Setiap negara membutuhkan sumber daya manusia yang berkualitas agar memberikan dampak positif terhadap perkembangan pembangunan suatu bangsa dalam berbagai bidang. Melalui pendidikan diharapkan tidak hanya menguasai ilmu pengetahuan dan teknologi, tetapi juga sikap mental yang baik.

Menurut Yamin (2013) secara tegas mengatakan bahwa pendidikan adalah media untuk mencerdaskan kehidupan bangsa dan membawa bangsa ini pada era aufklarung (pencerahan). Pendidikan bertujuan untuk membangun tatanan bangsa yang berbalut dengan nilai-nilai kepintaran, kepekaan, dan kepedulian terhadap

Copyright $@ 2020$, the Authors. Published by Redwhite Press.

Page | 82

This is an open access article under the CC BY-NC license

(http://creativecommons.org/licenses/by-nc/4.0). 
kehidupan berbangsa dan bernegara. Pendidikan merupakan tonggak kuat untuk mengentaskan kemiskinan pengetahuan, menyelesaikan persoalan kebodohan dan menuntaskan segala permasalahan bangsa yang selama ini terjadi.

Sistem pendidikan di Indonesia secara umum masih menitik beratkan pada kecerdasan kognitif. Hal tersebut dapat diamati dari orientasi lembaga pendidikan di Indonesia masih disibukan dengan rangkaian ujian seperti ujian tengah semester, ujian akhir semester, hingga ujian nasional. Sudah saatnya pemangku dan para pengambil kebijakan, pendidik, orang tua, serta masyarakat senantiasa memperkaya persepsibahwa ukuran keberhasilan bukan hanya diukur dari prestasi akademik saja, tetapi institusi pendidikan hendaknya menjadi tempat yang senantiasa menciptakan pengalaman bagi peserta didik untuk membangun dan membentuk karakter unggul.

Pemerintah Indonesia melalui kebijakan nasional pembangunan karakter bangsa menekankan perlunya pendidikan karakter bagi bangsa Indonesia dengan beberapa alasan (1) disorientasi nilai-nilai pancasila; (2) keterbatasan perangkat kebijakan terpadu mewujudkan nilai-nilai pancasila; (3) bergesernya nilai etika dalam kehidupan berbangsa dan bernegara; (4) memudarnya kesadaran terhadap nilai-nilai budaya bangsa; ancaman disintegrasi bangsa; dan (5) melemahnya kemandirian bangsa. (Buku Induk Kebijakan Nasional Pembangunan Karakter Bangsa 200-2025).

Melalui Undang-Undang No 20 Tahun 2003 tentang Sistem Pendidikan Nasional ditegaskan komitmen tentang pendidikan karakter sebagaimana termuat dalam rumusan fungsi dan tujuan penddidikan nasional. Pendidikan nasional berfungsi untuk mengembangkan kemempuan dan membentuk watak serta peradaban bangsa, serta bertujuan untuk berkembangnya petensi peserta didik agar menjadi manusia yang beriman dan bertaqwa kepada Tuhan Yang Maha Esa, berakhlak mulia, sehat, berilmu,cakap, kreatif, mandiri, dan menjadi warga negara yang demikratis dan bertanggung jawab.

Peraturan Pemerintah no 17 Tahun 2010 pasal 84 ayat 2, menyebutkan bahwa perguruan tinggi memiliki tujuan membentuk insan yang beriman dan bertaqwa kepada Tuhan Yang Maha Esa, berakhlak mulia, dan berkepribadian luhur, sehat, berilmu dan cakap, kritis, kreatif, inovatif, mandiri, percaya diri, dan berjiwa wirausaha, serta toleran, peka sosial dan lingkungan, demokratis dan bertanggung jawab.

Pelaksanaan pendidikan karakter di Indonesia saat ini dirasa sangat mendesak dan urgent bagi semua. Melihat situasi masyarakat, bahkan dunia pendidikan di Indonesia menjadi motivasi pokok untuk mengimplementasikan pendidikan karakter. Pendidikan karakter sangat perlu pengembangannya mengingat semakin banyak tawuran antar peajar, antar mahasiswa, serta bentuk kenakalan remaja lainya seperti kecenderungan dominasi senior terhadap yunior, penyalahgunaan narkotika, kekerasan, merusak fasilitas kampus, geng motor, dan lainnya. Dunia pendidikan memiliki tanggung jawab yang besar terhadap perkembangan generasi muda sehingga terhidar dari perilaku destruktif, anarkis, dan radikalis.

Universitas Pamulang disingkat UNPAM adalah salah satu perguruan tinggi swasta terbesar di Provinsi Banten dilihat dari sisi jumlah mahasiswa yang mencapai 85 ribu mahasiswa aktif mengikuti perkuliahan. Unpam didirikan pada tanggal 15 Mei 2000, alamat kampus utama berlokasi di Kecamatan Pamulang, Kota Tangerang Selatan. Tujuan dari Yayasan Sasmita Jaya yang menaungi unpam adalah mewujudkan suatu sarana pendidikan yang murah dan terjangkau oleh seluruh lapisan masyarakat tanpa melupakan kualitas dari pendidikan itu sendiri. Selain tujuan tersebut unpam memiliki visi, misi menciptakan sumber daya manusia yang berlandaskan nilai-nilai humanis dan religius. Latar belakang mahasiswa unpam sangat beragam.

Supaya terwujudnya pembentukan karakter yang diharapkan maka perlu adanya manajemen untuk mengelola implementasi manajemen pendidikan karakter pada ranah yang sesuai khususnya pada mahasiswa yang mejadi objek penanaman nilai-nilai karakter dalam kehidupan sehari-hari sehingga terbentuk mahasiswa yang berkarakter.

\section{METODE}

Penelitian ini merupakan penelitian dengan pendekatan kualitatif deskriptif, dengan metode fenomenologi. Data yang diperoleh baik yang bersifat primer maupun skunder akan diolah, dianalisis, dan diinterpretasikan secara kualitatif dimulai dengan analisa lingkungan internal dan eksternal yang merupakan penggambaran fenomena kondisi saat ini serta proyeksi yang akan datang untuk menentukan strategi alternatif. Menurut Sugiyono (2018) dalam penelitian kualitatif yang menjadi instrumen utamanya adalah peneliti itu sendiri. Sumber penelitian memanfaatkan sumber primer dan sumber skunder. Teknik pengumpulan data dalam menyelesaikan penelitian yaitu observasi (pengamatan), wawancara (interview), dan dokumentasi. 
Strategi dalam pengambilan sampel informan yang dipilih adalah secara purposif (purposive sample), yakni sampel yang didasarkan atas tujuan tertentu. Untuk menganalisis perkembangan informasi maupun sumbernya menggunakan prinsip "snowball sampling” yaitu teknik penentuan sampel yang mula-mula jumlahnya kecil, kemudian sampel ini memilih teman-temannya untuk dijadikan sampel semakin banyak. Penelitian ini dilaksanakan di Universitas Pamulang Tangerang Selatan, alamat J1. Surya Kencana No. 1, Pamulang Barat, Kecamatan Pamulang, Kota Tangerang SELATAN, Banten 15417.Adapun sampel dalam penelitian ini adalah Ketua Yayasan, Rektor, Tim Pendidikan Karakter (Warek 3), Kaprodi, Dosen, dan Mahasiswa.

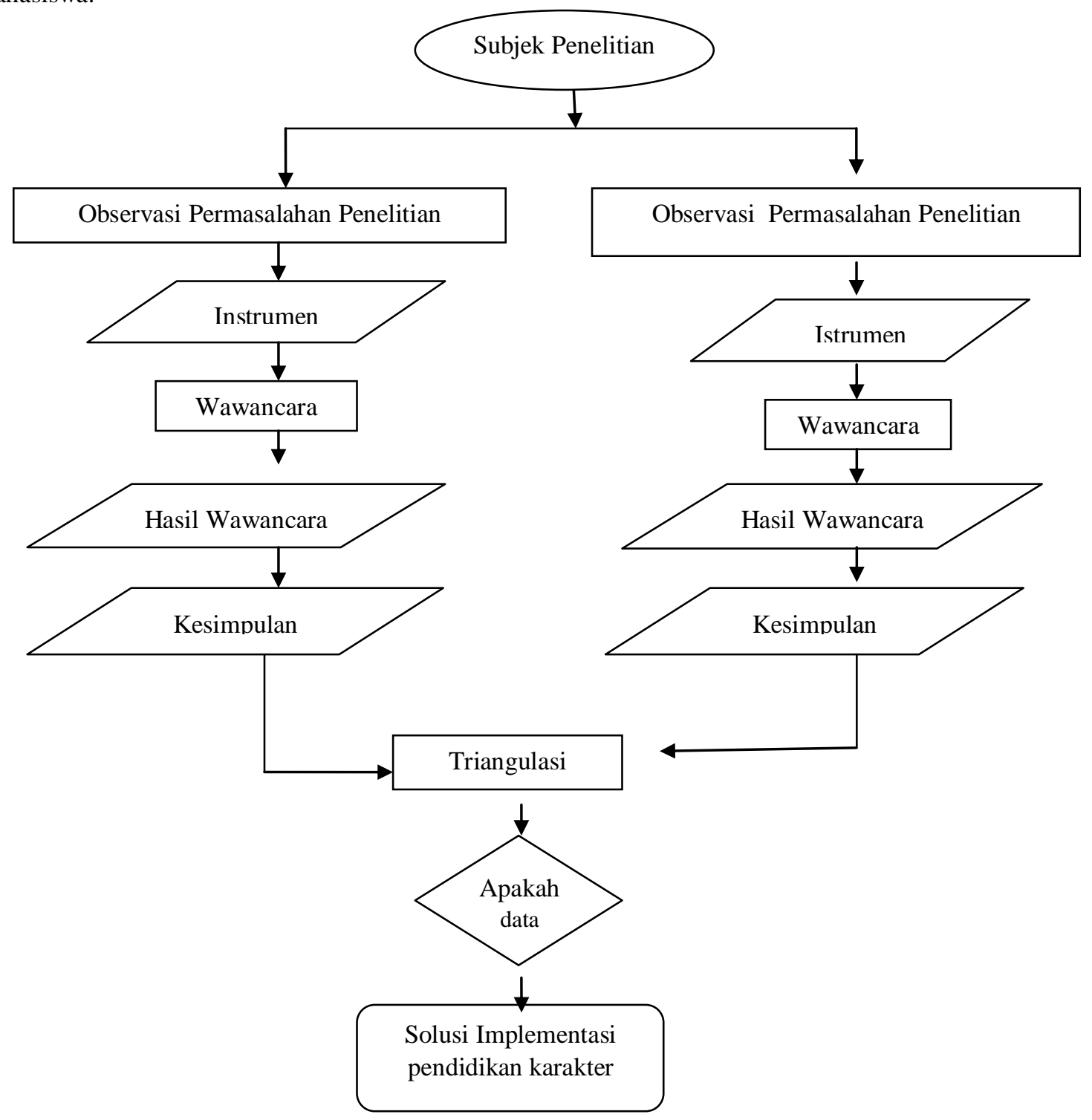

Gambar 1. Diagram Alur Prosedur

Keterangan:

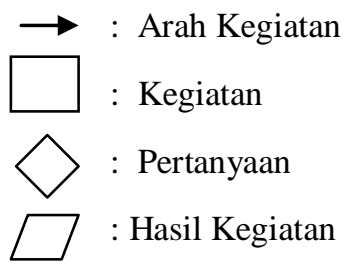


Analisis data dalam penelitian kualitatif bersifat induktif dimana data yang diperoleh akan dianalisis dan dikembangkan menjadi sebuah assumsi dasar. Komponen-komponen yang harus dipahami diantaranya: pengumpulan data (data collection), reduksi data (data reduction), penyajian data (data display), dan penarikan kesimpulan (conclusion drawing/verification). Dalam proses penelitian setelah data yang dikumpulkan dan diperoleh, tahap berikutnya yang penting adalah melakukan analisis dengan menggunakan analisis secara deskriptif-kualitatif yaitu teknik yang menggambarkan dan menginterpretasikan arti data-data yang telah terkumpul melalui fakta-fakta, sifat-sifat, serta hubungan antar fenomena yang diselidiki.

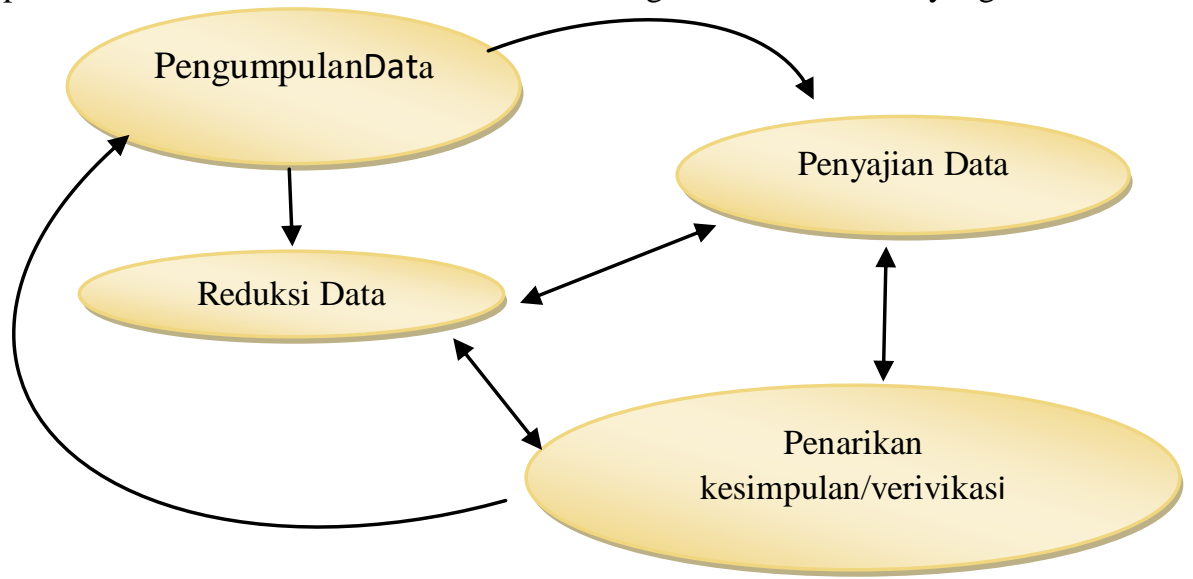

Gambar 2. Prosedur Analisi DataInteraktif Miles \& Huberman

Teknik analisi data yang digambarkan pada gambar di atas digunakan untuk menganalisis data pada masing-masing dsitus atau lokasi penelitian menurut Miles \& Huberman (1994). Teknik analisi data dilakukan secara interaktif dan berlangsung secara terus menerus sampai tuntas, sehingga datanya jenuh.

\section{HASIL DAN PEMBAHASAN}

Manajemenpendidikan karakter merupakan pengelolaan tata nilai dan aktivitas pendidikan yang dijabarkan dalam tahapan-tahapan manajemen yaitu Planning, Organizing, Actuating, Controlling. Robbins and Coulter dalam Yenny dan Nisak (2020) mendefenisikan bahwa "management involes coordinating and overseeing the work activities of others so that their activities are completed effecienyly and effectively". Sedangkan menurut George Terry dalam Wibowo (2013) "management is a distinct process consisting of planning, organizig, actuating, and controling, performed todetermine and accomplish stated objetctives by the use of human beings and other resources". Manajemen adalah suatu proses perencanaan, pengorganisasian, pelaksanaan, dan pengontrolan melalui orang lain atau sumber daya lain untuk mewujudkan tujuan. Proses yang dikemukakan Terry inilah yang secara populer dikenal dengan singkatan POAC (Planning, Organizing, Actuating, Controlling).

Menurut Kurniadi dan Machali (2012) manajemen adalah usaha memanage (mengatur) organisasu untuk mencapai tujuan yang ditetapkan secara efektif dan efisien. Efektif berarti mampu mencapai tujuan dengan baik, sedangkan efisien berarti melakukan sesuatu dengan benar. Beberapa defenisi manajemen menurut para ahli dapat disimpulkan manajemen adalah megatur organisasi secara efektif dan efisien sesuai dengan fungsi-fungsi manajemen yaitu perencanaan, pengorganisasian, pelaksanaan, dan pengontrolan dalam mencapai tujuan organisasi yang telah ditetapkan.

Menurut Abdul dan Dian (2010) istilah katakter berasal dari bahasa latin "Character" yang berarti watak, tauiat, sifat-sifat kejiwaan, budi pekerti, kepribadian atau akhlak. Istilah karakter dapat diartikan sebagai sifat kejiwaan, akhlak atau budi pekerti yang menjadi ciri khas seseorang atau sekelompok orang. Sedangkan menurut Yahya (2010) karakter juga bisa diartikan sikap, tabiat, akhlak, kepribadian yang stabil sebagai hasil proses konsolidasi secara progresif dan dinamis.Ki Hadjar Dewantara dalam Aryanto telah jauh berfikir dalam masalah pendidikan karakter. Mengasah keserdasan budi sungguh baik, karena dapat membangun budipekerti yang baik dan kokoh, hingga dapat mewujudkan kepribadian dan karakter (jiwa yang berasas hukum kebatinan). Jika itu terjadi orang akan senantiasa dapat mengalahkan nafsu dan tabiattabiatnya yang asli (bengis, murka, pemarah, kikir, keras, dan lainnya).

David Elkind dalam Zubaedi (2011) mengatakan bahwa character education is the deliberate effort to help people understand, care about, act upon care ethical value. When we think about the kind of character we want for our children, is is clear that we want them to be able to judge what is right, even in the face of 
pressure from without and temtation from within. Lickona (1992) mendefenisikan pendidikan karakter sebagai upaya yang sungguh-sungguh untuk membantu seseorang memahami, peduli dan bertindak dengan landasan nilai-nilai etis. Pendidikan karakter mengandung tiga unsur pokok yaitu megetahui kebaikan (knowing the good), mencintai kebaikan (desiring the good), dan melakukan kebaikan (doing the good). Oleh karena itu, orang yang berkarakter diartikan sebagai sifat alami seseorang dalam merespons situasi secara bermoral yang dimanisfetasikan dalam tindakan nyata melalui tingkah laku yang baik, jujur, bertanggung jawab, menghormati orang lain dan tentu karakter mulia lainnya. Manajemen pendidikan karakter merupakan pengelolaan tata nilai dan aktivitas pendidikan yang dijabarkan dalam tahap-tahap manajemen yaitu perencanaan, pegorganisasian, pelaksanaan, pengontrolan/evaluasi.

\section{Perencanaan Implementasi Pendidikan Karakter}

Robbins \& Coulter (2012) yang mendefenisikan "perencanaan sebagai sebuah yang ditandai dari penetapan tujuan organisasi, menetapkan strategi untuk mencapai tujuan organisasi tersebut secara menyeluruh untuk mengintegrasikan dan mengkoordinasikan seluruh pekerjaan organisasi hingga tercapainya tujuan organisasi". Planning is a process that involves defining the organization's goals, establishing an overall strategy for achieving those goals, and developing a comprehensive set of plans to integrate and coordinate organizational work.

Usman (2011) perencanaan adalah merupakan kegiatan yang dilakukan dimasa yang akan datang untuk mencapai tujuan yang mengandung unsur-unsur: (a) sejumlah kegiatan yang ditetapkan sebelumnya; (2) adanya proses; (3) hasil yang dicapai; dan (4) berkaitan dengan masa depan dalam waktu tertentu. Perencanaan tidak akan terlepas dari unsur pengkoordinasian, pelaksanaan, dan pengawasan, penilaian serta pelaporan. Pengawasan dilakukan supaya tidak terjadi penyimpangan-penyimpangan.Rahman (2019) Perencanaan manajemen Pendidikan berbasis karakter termaktub dalam manajemen berbasis sekolah, yang memuat wewenang yang diberikan kepala sekolah untuk mengatur sendiri rumah tangga sekolahnya.

Kedua teori dan hasil penelitian dapat disimpulkan bahwa Universitas Pamulang telah melakukan perencanaan sesuai dengan teori-teori. Beberapa pendapat para ahli di atas dengan manajemen Universitas Pamulang tentang tahap-tahap perencanaan manajemen sekolah memiliki perbedaan, yaitu: (1) hal-hal yang mendasari kegiatan penerapan pendidikan karakter, (2) urutan-uratan perencanaan manajemen penerapan pendidikan karakter. Selain itu juga mempunyai kesamaan yaitu dalam hal untuk mencapai tujuan manajemen pendidikan karakter.

Perbedaan dan persamaan tersebut, maka kelebihan implementasi manajemen pendidikan karakter di universitas pamulang dalam perencanaannya adalah sebagai berikut: (1) ada penetapan tujuan diadakannya Implementasi pendidikan karakter; (2) ada pembentukkan tim dalam implementasi pendidikan karakter; (3) ada sasaran dari program kegiatan pembentukan karakter; (4) ada jadwal kegiatan pembentukan karakter; (5) ada waktu kapan dimulainya kegiatan tersebut. Sedangkan kekurangan dalam merencanakan kegiatan tersebut adalah tidak semua dosen terlibat dalam kegiatan penerapan pendidikan karakter karena hanya tim dan dosen tertentu yang konsendalam kegiatan ini. Hal tersebut dibuktikan dalam proses observasi peneliti hanya dosen-dosen tertentu, dosen agama dan tim warek 3, tidak seluruh mahasiswa yang rutin mengikuti rangkaian kegiatan dalam menguatkan dan implementasi pendidikan karakter di universitas pamulang.

Pengorganisasian Implementasi Pendidikan Karakter

Hidayat dan Machali (2015) pengorganisasian adalah suatu kegiatan pengaturan atau pembagian pekerjaan yang dialokasikan kepada sekelompok orang atau karyawan yang dalam pelaksanaannya diberikan tanggung jawab dan wewenang. Sehingga tujuan organisasi dapat tercapai secara efektif, efisien, dan produktif.Pengorganisasian di universitas pamulang termasuk dalam kegiatan penetapan tugas, tanggung jawab dan wewenang rektor, dosen, dan tim penerapan pendidikan karakter serta mekanisme pelaksanaan program kerja sehingga dapat menjamin tercapaianya visi, misi dan tujuan Universitas Pamulang.

Hasil penelitian menurut Suparlan dan Syukri Fathudin AW (2017) Langkah-langkah pengorganisasian: (a) Pembentukan organisasi pendidikan karakter berbasis pembelajaran PAI yang terdiri dari unsur: Birokrat/pelaksana perguruan tinggi, Stakeholder eksternal, dosen, mahasiswa, (b) Pengorganisasian level universitas, (c) Pengorganisasian level fakultas, (d) Pengorganisasian level dosen melibatkan sesama dosen dan dosen dengan mahasiswa, (e) Pengorganisasian level mahasiswa melibatkan mahasiswa senior dan mahasiswa junior, (f) Analisis organisasi internal dan eksternal.

Kedua teori dan hasil penelitian dapat disimpulkan bahwa implementasi manajemen pendidikan karakter di universitas pamulang melakukan mengorganisasian sebagai berikut: organisasi yang masuk dalam kegiatan implementasi pendidikan karakter (a) Pelatihan Soft Skill berorganisasi, (b) Konseling individu atau kelompok, (c) Pembinaan mental dalam menghadapi kompetisi baik di tingkat lokal dan nasional, (d) 
memperingati hari besar Islam, (e) seribu senyum untuk sahabat, (f) KUM (Kampus Unpam Mengaji),(g) dan satu meter bebas sampah dalam kepedulian terhadap lingkungan sekitar setiap hari.

Penelitia tersebut terdapat perbedaan yaitu: di Universitas Pmulang melibatkan beberapa organisasi yang ada (Lembaga Kajian Keagamaan, Himpunan Mahasiswa Jurusan). Sedangkan persamaannya yaitu: (1) pembentukan program-program kegiatan yang akan dilaksanakan, (2) pembagian tugas dan wewenang, dan (3) pengalokasian sarana prasarana dan pembiayaan.

\section{Pelaksanaan Implementasi Pendidikan Karakter}

Hidayat dan Machali (2015) menjelaskan penggerakkan (actuating) adalah salah satu fungsi manajemen yang berfungsi untuk merealisasikan hasil perencanaan dan pengorganisasian.Hasil penelitian. Teori dan hasil penelitian dapat disimpulkan bahwa universitas pamulang juga menggerakkan kegiatan penerapan nilai karakter dan telah sesuai dengan penelitian salim. Penggerakan yang dilakukan universitas pamulang antara lain: (1) mahasiswa terlibat dalam setiap kegiatan; (2) mahasiswa ikut serta memberi motivasi kepada sesama temannya dengan cara menjadi teladan terlebih dahulu dengan kata lain dimulai dari diri sendiri.Namun masih ada mahasiswa yang masih bersikap acuh atau tingkat kesadaran diri belum maksimal ketika tidak diberitahu atau diperintah sama dosen belum tentu mengikuti aturan atau kegiatan penerapan pendidikan karakter.

\section{Pengawasan Implementasi Pendidikan Karakter}

Robbins dan Coulter (2012) menyatakan: "Management involves coordinating and overseeing the work activities of others so that their activities are completed efficiently and effectively". Manajemen melibatkan koordinasi dan mengawasi kegiatan kerja orang lain sehingga kegiatan mereka selesai dengan cara efisien dan ejektif.Malayu (2014) mengatakanbahwa "tujuan koordinasi yaitu sebagai berikut :

1) Untuk mengarahkan dan menyatukan semua tindakan serta pemikiran kea rah tercapainya sasaran perusahaan

2) Untuk menjuruskan keterampilan spesialis kearah sasaran perusahaan

3) Untuk menghindari kekosongan dan tumpang tindih pekerjaan

4) Untuk menghindari kekacauan dan penyimpangan tugas dari sasaran

5) Untuk mengintegrasikan tindakan kearah sasaran organisasi atau perusahaan

6) Untuk menghindari tindakan overlapping fari sasaran perusahaan".

Menurut Rahman (2019) Evaluasi pendidikan karakter meliputi pengendalian dan evaluasi sumatif. Pengendalian dipahami sebagai penilaian proses pelaksanaan pendidikan karakter. Dalam pembelajaran, penilaian proses disebut sebagai formatif. Penilaian ini merupakan faktor kritis keberhasilan pembelajaran yang efektif.Hasil penelitian rahman adanya kesamaan dalam implementasi pendidikan karakter, menunjukkan bahwa dengan adanya pengedalian dan evaluasi peserta kegiatan penerapan pendidikan karakter telah memahami pentingnya pendidikan karakter dan sebagaian besar dosen telah mulai melakukan implementasi nilai-nilai karakter kepada mahasiswa.

\section{Kendala Implementasi Pendidikan Karakter}

Kendala yang dihadapi pada implementasi manajemen karakter di Universitas Pamulang yaitu terbatasnya sumber daya manusia (dosen, tim penerapan pendidikan karakter, mahasiswa), yang bergerak aktif dalam semua program-program atau kegiatan implementasi pendidikan karakter.

\section{SIMPULAN}

Hasil penelitian implementasi manajemen pendidikan karakter di Universitas Pamulang: Pertama, perencanaan menanamkan kesadaran bersama dan menyamakan persepsi pentingnya pengintegrasian nilai atau karakter. Kedua, pengorganisasian membagikan tugas dan wewenang serta tanggung jawab kepada seluruh dosen terkhusus dosen agama, tim pendidikan karakter (Warek 3). Ketiga, pelaksanaan berupa kegiatan akademik, kegiatan non akademik, cara dan proses meningkatkan kegiatan. Keempat, pengawasan melihat ketercapaian implementasi pendidikan karakter yang telah dirasakan oleh pihak Yayasan, Rektor, dosen, tim warek 3, dosen agama, dan mahasiswa. Adapun kendala dalam implementasi manajemen pendidikan karakter di Universitas Pamulang yaitu terbatasnya sumber daya manusia yang bergerak aktif dalam menerapkan semua program atau kegiatan yang ada. 


\section{REFERENSI}

Abdul, majid., Dian, andayani. (2010). Pedidikan karakter dalam perspektif Islam. Bandung: Insan Cita Utama.

Hasanah, Yenny. M., \& Husnul, Nisak RI. (2020). Strategies In Alleviating Gepeng (Homeless People and Beggars) In Jabodetabek. ICOLEESS (295-303) : International Conference on Language, Education, Economic and Sosial Science. IAI Pangeran Diponegoro.

Hidayat dan Machali. (2015). The Handbook of Education Management (Teori dan Praktik Pengelolaan Sekolah/Madrasah di Indonesia. Jakarta: Prenadamedia Group.

Kurniadi, DidindanMachali, Imam.(2014). ManajemenPendidikan. Yogyakarta: Ar-Ruzz Media

Malayu S.P. Hasibuan. (2014).Manajemen Dasar, Pengertian, dan Masalah.Jakarta: PT Bumi Aksara.

Miles, M.B., \& Huberman, A.M. (1994). An expanded sourcebook qualitative data analysis. Thousand Oaks: SAGE Publications.

Pemerintah Republik Indonesia. (2010). Pembangunan Karakter Bangsa Tahun 2010-2025: Desain Induk. Jakarta.

Peraturan Pemerintah Republik IndonesiaNomor 17 tahun 2010 pasal 84 ayat 2. Jakarta.

Republik Indonesia.(2003). Undang-Undang RI Nomor 20, Tahun 2003, tentang Sistem Pendidikan Nasional.

Robbins, Stephen P., and Mary Coulter. (2012). Management. 11th. Prentice Hall., New Jersey.

Sugiyono. (2018). Metode Penelitian Kuantitatif, Kualitatif, dan R\&D. Bandung: Alfabeta.

Suparlan, AW Fathudin, Syukri. (2017). Manajemen Pendidikan Berbasis Pembelajaran Pendidikan Agama Islam di Perguruan Tinggi Umum. Jurnal Humanika

Taufiqur Rahman. (2019). Implementasi Manajemen Pendidikan Karakter dalam Pembinaan Akhlak Peserta Didik. Jurnal Pendidikan Islam Indonesia. Volume 4 (1).

Usman, Husaini. (2011). Manajemen (Teori, Praktik dan Riset Pendidikan) Edisi 3. Jakarta Timur: PT Bumi Aksara.

Wibowo, Agus. (2013). Manajemen Pendidikan Karakter Di Sekolah. Yogyakarta: Pustaka Pelajar.

Yahya Khan. (2010). Pendidikan Karakter Berbasis Potensi Diri: Mendongkrak Kualitas Pendidikan. Yogyakarta: Pelangi Publishing

Yamin, Mohammad. (2013). Ideologi dan kebijakan pendidikan. Malang: Madani

Zubaedi. (2011). Desain Pendidikan karakter, Konsepsi dan Aplikasinya dalam lembaga Pendidikan. Jakarta: Kencana Prenada Media Group. 